\title{
BIM Promotion Plan in Civil Engineering through the Analysis of the User Recognition Changes
}

\author{
Ki Beom Ju, Myoung Bae Seo \\ ICT Convergence and Integration Research Division, \\ Korea Institute of Construction Technology, Goyang-Si, Republic of Korea \\ Email: kbju@kict.re.kr, smb@kict.re.kr
}

Received September 2013

\begin{abstract}
BIM, which recently emerged as a hot issue in the construction industry, is being recognized as a new breakthrough for the industry. However it is now in crisis due to the stagnant construction business and the decrease in the amount of orders. Already, various studies are being conducted to introduce BIM to architecture both domestically and abroad, but in civil engineering projects, unlike in construction projects, the work system is non-repetitive, horizontal, and atypical, and the scope of the project tasks is so wide that the amount of information generated is vast. As a result, construction companies and designers feel burdened by the initial investment cost for BIM construction and have doubts about its cost-effectiveness. As such, to implement BIM in domestic civil engineering projects, this study determined the BIM technology level of designers in civil engineering and analyzed the changes in their awareness of BIM from the past so as to determine the obstacles to BIM activation in civil engineering and to propose a solution for such. The results of this study are expected to be used as the basic data for setting the direction of the research on the standard for introducing BIM to civil engineering and on the development of a receipt inspection and verification system for supplied products.
\end{abstract}

Keywords: BIM; Standard; Civil Engineering; Activation; Change in Awareness; Information Model

\section{Introduction}

BIM (Building Information Modeling) is emerging as a new paradigm for improving the productivity of construction projects. BIM can be defined as "a technique for producing and controlling all information applied to various areas during the life cycle of structures, from their planning and designing to their maintenance and control". As opposed to construction projects, where BIM is actively being implemented, civil engineering projects have a non-repetitive, horizontal, and atypical work system, and their project scope is too wide that the amount of information generated is vast, causing constructors and designers feel burdened by the initial investment cost for BIM construction and to have doubts about its cost-effectiveness (Leen Seok, K., Seol Gi, K., Hyeon Seong, K., \& Hyoun Seok, M., 2011). These reasons, however, are still not enough to explain the delayed introduction of BIM to civil engineering projects, which would have a huge impact on the country's economy. It is also difficult to determine what would be needed first to solve these problems.

This study thus aimed to analyze the changes in the BIM awareness of the civil engineering designers who are either using BIM at work or have a higher understanding of it, to determine the related problems and to propose solutions to these. In particular, the various factors preventing the introduction of BIM were extracted from the current time and social needs but not from an activation plan based on superficial surveys, or by analyzing the awareness changes from the past, where there was a lack of social awareness of BIM, as well as the current status of the initial introduction of BIM, and based on the extraction results, this study aimed to propose a BIM activation plan.

\section{Review of Factors That Impede BIM Activation}

According to the results of the survey published in the US SmartMarket Report in 2008, the factors that impede the application of BIM are the lack of pertinent education and of BIM specialists, the initial BIM cost, the lack of determination to introduce BIM, and the insufficient compensation (McGraw Hill Construction, 2008). For the problems, Bae pointed out the absence of standards for storing information in the existing 3D models and the fixation of the 2D-drawing-centered supply system (Kyoung Jin, B. \& Han Jong, J., 2010). Kyoung Jin also discussed as the factors hindering the compatibility of the BIM software: the absence of a domestic standard information model, the establishment of the BIM process and its technical limitations, the lack of standard/guidelines/references/actual cases, the lack of specialists on BIM tools, and the need for governmental support (Jung Wook, P., Sang Chul, K., Sang Soo, L., \& Ha Young, S., 2009). Jong Cheol argued for the urgent development of guidelines, including those on education, license acquisition, data compatibility, and ownership, as well as for systemic establishment (Jong Cheol, S. \& In Han, K., 2009). $\mathrm{Na}$ et al. also discussed the lack of BIM specialists, the initial cost of SW purchase and technical training, and the lack of standardization for the process categorization and cost categorization systems (Kyung Jae, N., Kyoung Hwan, J., Dong-Gun, L., \& Hee Sung, C., 2008). Meanwhile, Ha Neul pointed out the lack of awareness of BIM, the stagnant domestic construction market, the cooperative structure that is in conflict with the BIM method, and the lack of specialists as the hindering factors 
(Ha Neul, P. \& Young-Sam, H., 2010).

These factors, however, are expected when BIM is implemented in domestic construction projects, or from foreign BIM introduction cases focusing on a small number of construction companies, and do not evenly reflect various interest parties, such as companies that have not implemented BIM, that are about to implement it, and large and small companies. Therefore, to determine the importance level of BIM activation, an additional survey is necessary.

\section{Analysis of the BIM Awareness Changes in Civil Engineering}

\section{Introduction}

An analysis of awareness changes is required to determine the identical items or similar targets in time difference. Therefore, this study extracted the identical survey items based on those used by Korea Institute of Construction Technology in 2010 in relation to the BIM awareness of engineering companies, which consisted of nine items in three groups: three items for BIM application, three items for the area of BIM application and the hindering elements, and three items for the demand diffusion effect when BIM is used (Table 1). For the survey, two interviews were conducted in June and July 2012 with 25 people from the 25 top subcontractors in South Korea. Through a comparison of the results of the survey conducted in this study to those of the 2010 survey, the BIM application level in 2010, the matters that need to be considered, and the demand diffusion effect were determined. For easier comparison, the 5 -point criteria were converted into a $100 \%$ average.

\section{Changes in the Awareness of the BIM Application Level}

The converted average of the changes in the awareness of the BIM usage increase rate by year was 56.1 in 2010, and this decreased to 52.8 in 2012. Also, the change in the awareness of the importance of BIM by year was 82.8 in 2010, which also decreased to 78.7 in 2012 (Figure 1).

Particularly noteworthy in the survey results on the changes in the awareness of the BIM-applied tasks is the fact that the

Table 1.

Survey items.

\begin{tabular}{|c|c|c|}
\hline Group & Question & Response Type \\
\hline \multirow{3}{*}{ BIM application } & BIM usage increase rate by year & Short-answer \\
\hline & $\begin{array}{l}\text { Change in the perceived } \\
\text { importance of BIM }\end{array}$ & 5-point \\
\hline & BIM-applied tasks & Compound option \\
\hline \multirow{3}{*}{$\begin{array}{l}\text { Things to consider } \\
\text { when using BIM }\end{array}$} & $\begin{array}{l}\text { BIM solution use effectiveness } \\
\text { level }\end{array}$ & 5-point \\
\hline & $\begin{array}{l}\text { Factors hindering the use } \\
\text { of BIM }\end{array}$ & 5-point \\
\hline & $\begin{array}{l}\text { What is needed to have BIM } \\
\text { established at work }\end{array}$ & Single selection \\
\hline \multirow{3}{*}{$\begin{array}{l}\text { Demand diffusion } \\
\text { effect }\end{array}$} & Assessment of BIM effect & 5-point \\
\hline & $\begin{array}{l}\text { Change in the internal profits } \\
\text { and application }\end{array}$ & Degree of change \\
\hline & Key factors of BIM application & 5-point \\
\hline
\end{tabular}

awareness of the effectiveness of BIM on facilities maintenance and control showed the largest change. This result is due to the decrease in the number of new civil engineering projects and the increase in the maintenance and control costs in recent years, and it is believed that such result reflected the expectation that the appropriate implementation of BIM makes it easy to determine the life cycle of buildings and the exchange cycle of facilities so that its application in the facilities maintenance and control stage will have a very large impact. Also, it was determined that further research is required to help improve various types of decision-making processes, such as measuring the value of public facilities, predicting the rate of deterioration, and efficiently distributing the maintenance and control budget by increasing the visual effects through the combination of the facility information and the information on the existing topography based on GIS, etc. (Figure 2).

\section{Changes in the Awareness of the Matters to Be Considered and of the Demand Diffusion Effect When Using BIM}

The results of the survey on the changes in the awareness of the effects of the use of the BIM solution showed that while the awareness of the improvement of the project design quality, the enhancement of the construction and maintenance functions, and the improvement of communication among various parts of the design and other phases of construction increased, there was also a change in the awareness that the project performance

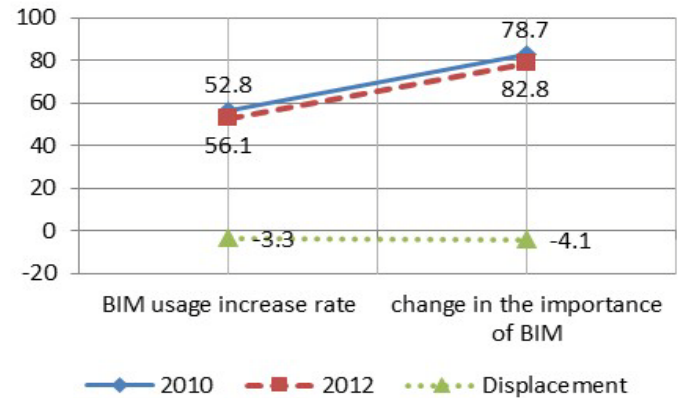

Figure 1.

Changes in the BIM usage increase rate and BIM importance awareness.

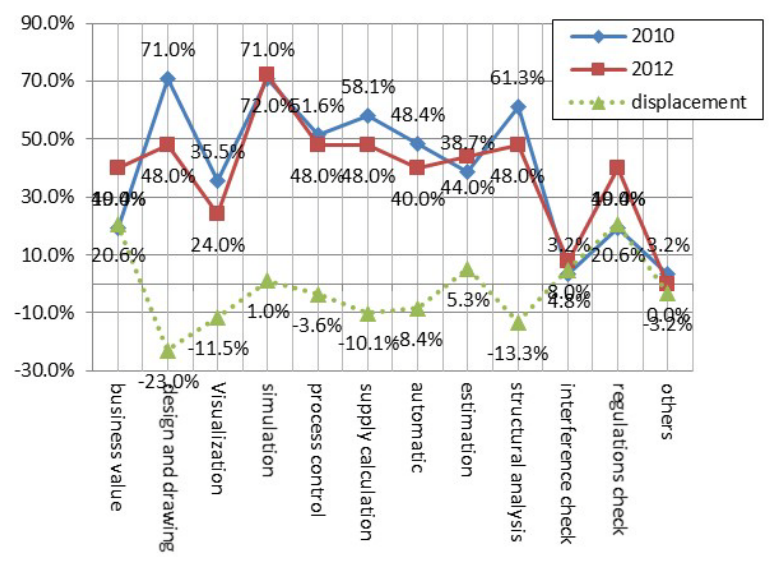

Figure 2.

Awareness changes in the BIM-applied tasks. 
speed would increase and that the construction cost would rise drastically. The high displacement on the effect of the improvement of communication among all the parts of the design and construction phases signifies that while BIM modeling was recognized in the past as something that would solve all problems, the real function of BIM has now been realized. While BIM may mean cost increase for designers in the short term, in the long term, it will revive the construction industry by creating a new construction market. As such, various efforts to correct the interested parties' negative preconceptions of the introduction of BIM are currently being exerted (Figure 3).

As for the survey on the awareness change in the areas required for the establishment of BIM at work, the view that government-led planning/policies and standards would be necessary was relatively higher than the others. Particularly noteworthy is the over $33 \%$ change in the need for business value/efficiency review for the implementation of BIM at work, showing that many institutions want a soft landing rather than the implementation of drastic changes to the BIM system, after sufficient preliminary reviews. Furthermore, it is shown that public institutions should consider a new ordering system including BIM to expand the BIM market in civil engineering (Figure 4).

\section{Proposed BIM Activation Plan in Civil Engineering}

Compared to 2010, the initial phase of BIM introduction, the $\mathrm{BIM}$ recognition level in civil engineering has increased overall, but the BIM usage increase rate or importance level awareness has decreased. The key factors accounting for such a result may include the lack of BIM-related demands, the absence of regulations or guidelines related to BIM, and the difficulty of investing as it is difficult to recognize the time needed for and cost of substituting 2D products with $3 \mathrm{D}$ products. To solve these problems, it was determined that the effects of BIM should be actively promoted by discovering various application cases according to the introduction of BIM, changing the delivery/contract/business management processes based on the BIM ordering system, and analyzing the business value, and in tandem, the government should revise regulations and systems and develop related standards. In addition, further research is required to develop plans to make construction projects competitive by combining the mobile, clouding, GIS, and other state-of-the-art IT technologies and by sharing, exchanging, and utilizing construction information.

An analysis of the awareness changes should focus more on the differences than on the similarities, which means that the BIM awareness of the companies that have experienced BIM implementation has changed in the process of the implementation, and accordingly, various activation plans could be proposed to proactively cope with such a change.

Whereas in the past the key BIM tasks were either simulation or interference check, nowadays the users are recognizing the demand for the use of BIM in facilities maintenance and control as well as the importance of the cooperation between the designer and the contractor, which is the basis for determining that the users' overall understanding of BIM has improved. The fact, however, that according to pertinent reports or reviews, the business value and efficiency of the BIM implementation at work has increased by over $35 \%$ shows that to satisfy the

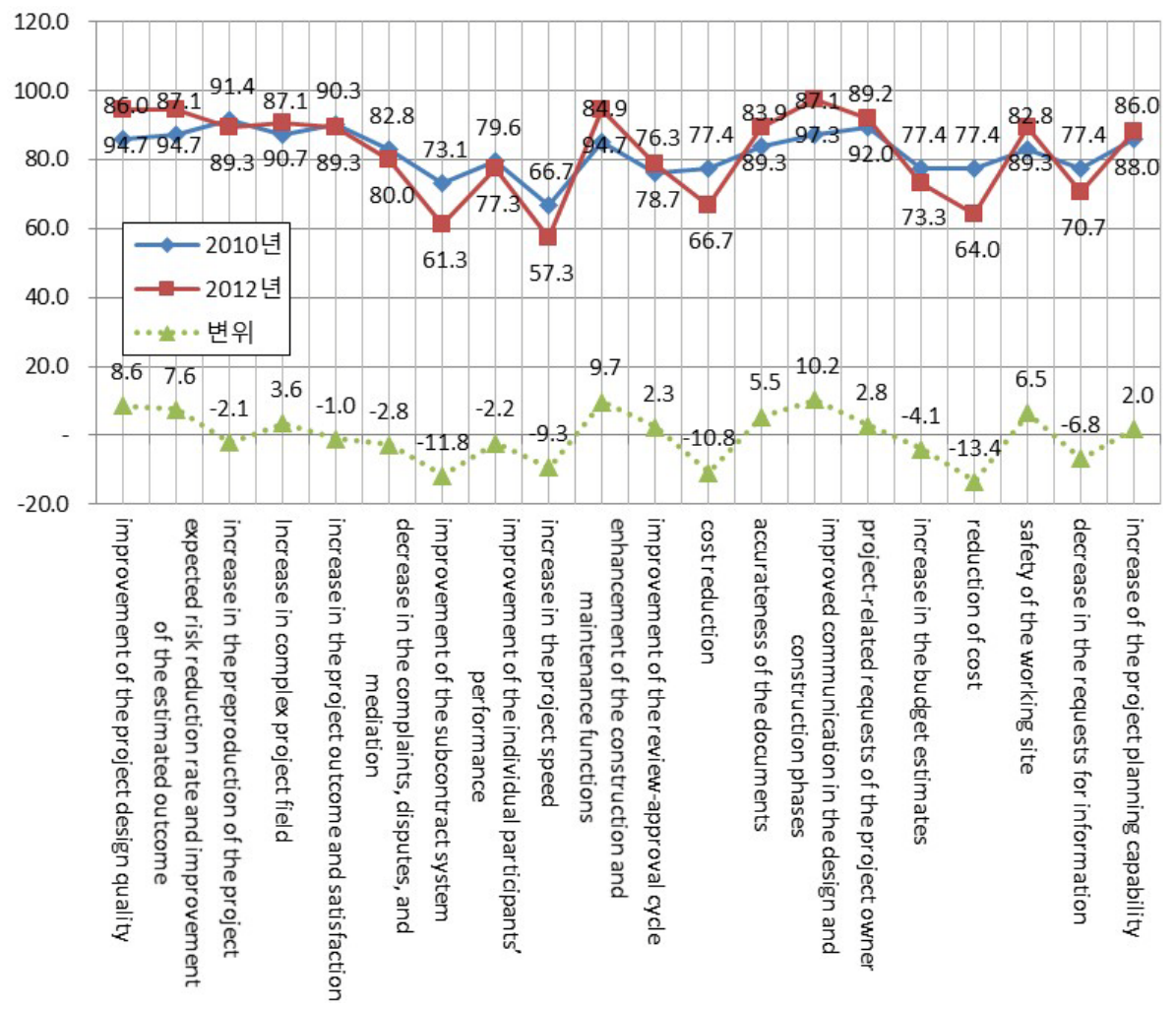

Figure 3.

Changes in the effects of the use of the BIM solution. 


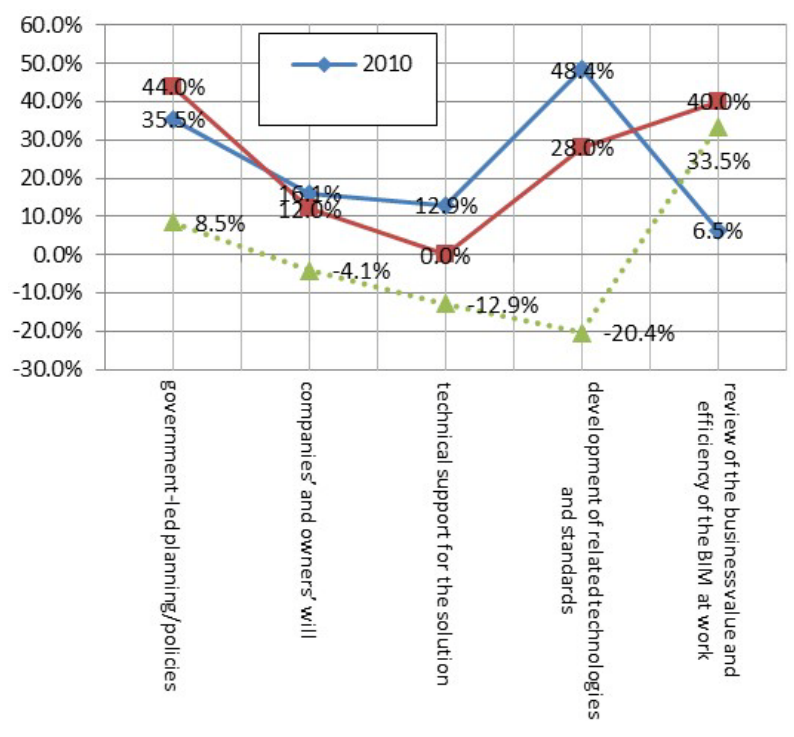

Figure 4.

Awareness changes in the areas required for the establishment of BIM at work.

higher expectation of the users and to activate BIM, it is important not only for the government to actively promote BIM but, more importantly, to assure the users that their profits will increase when they use BIM, and to promote the designers' and contractors' proactive participation as well as not to effect a drastic change in the BIM system but to effect the system's soft landing.

\section{Conclusion}

This article proposed various BIM activation plans by analyzing the changes in BIM awareness. The proposed plans are significant in that they show the future direction of the BIMrelated research that is to be actively conducted in civil engineering. It was also determined that the results of this study can be used by companies that plan to introduce BIM as these can help them determine in advance the various factors that may hinder BIM introduction, and minimize the errors in such endeavor. Furthermore, the proposed activation plans should be realized in the mid- to long term, not allowing short-term outcomes but a natural change towards the BIM ordering system based on the cooperation among the industry, academe, research, and government sectors.

\section{Acknowledgements}

This study was part of Development of Infra BIM Standard and Verification Technology, a key project (13 key tasks) of KICT (Korea Institute of Construction Technology).

\section{REFERENCES}

Ha Neul, P., \& Young Sam, H. (2010). Research on survey analysis on the current status of BIM application on small and medium sized architecutral design offices, 30th Korean Construction Conference, No. 1, 109-110.

Jong Cheol, S., \& In Han, K. (2009). A study on the basic directions for introducing and applying building information modeling in public construction project delivery. Proceedings of Architectural Institute of Korea, Structure, 25, 21-30.

Jung Wook, P., Sang Chul, K., Sang Soo, L., \& Ha Young, S. (2009). Suggesting solutions when applying building information modeling (BIM) to the South Korean construction industry through case studies. Journal of Korea Institute of Building Construction, 9, 93-102.

Kyung Jae, N., Kyung Hwan, J., Dong Gun, L., \& Hee Sung, C. (2008) Development of a conceptual-process model for BIM application in the South Korean construction industry. Proceedings of Korea Institute of Construction Engineering and Management, 649-653.

Kyoung Jin, B., \& Han Jong, J. (2010). A study on the barriers to the adoption of BIM and the changes in mind BIM. Proceedings of Architectural Institute of Korea, Planning, 1, 111-112.

Leen Seok, K., Seol Gi, K., Hyeon Seong, K., \& Hyoun Seok, M. (2011). BIM application for civil engineering project in planning and design phases. Journal of KIBIM, 1, 26-31.

McGraw Hill Construction (2008). SmartMarket report. New York: McGraw Hill. 